\title{
Association of Protein Expression and Methylation of DAPK1 with Clinicopathological Features in Invasive Ductal Carcinoma Patients from Kashmir
}

\author{
Asia Asiaf', Shiekh Tanveer Ahmad², Ajaz Ahmad Malik³, Shiekh Aejaz Aziz ${ }^{4}$, \\ Mohammad Afzal Zargar ${ }^{1 *}$
}

\begin{abstract}
Aims: Death-associated protein kinase-1 (DAPK1) is a pro-apoptotic Ser/Thr kinase that participates in cell apoptosis and tumor suppression. DAPK1 is frequently lost in many different tumor types including breast cancer. The aim of this study was to evaluate the promoter methylation status of DAPK1 and a possible correlation with the expression of DAPK1 and standard clinicopathological features in invasive ductal breast carcinoma patients (IDC). Methods: Methylation Specific PCR (MSP) was carried out to investigate the promoter methylation status of DAPK1 from 128 breast cancer patients. The effect of promoter methylation on protein expression was evaluated by immunohistochemistry $(\mathrm{n}=128)$ and western blotting $(\mathrm{n}=56)$. Results: We found significant difference in DAPK1 promoter methylation frequency among breast tumors when compared with the corresponding normal tissues. Hypermethylation of DAPK1 is significantly correlated with the loss of DAPK1 protein expression $(\mathrm{P}<.001, \mathrm{rs}=-0.361)$. The loss of DAPK1 protein was significantly associated with estrogen receptor $(\mathrm{ER})$ negativity $(\mathrm{p}=0.003)$, triple negative breast cancer $(\mathrm{TNB})$ $(\mathrm{p}=0.024)$ and advanced tumor stages $(\mathrm{P}=0.001)$. Moreover, age at diagnosis $(\mathrm{p}=0.041)$, tumor stage $(\mathrm{p}=0.034)$, ER negativity $(\mathrm{p}=0.004)$ and TNB cancers $(\mathrm{p}=0.003)$ correlated significantly with the hypermethylation of the DAPK1 promoter. Coclusion: This study indicates that DAPK1 is methylated in IDC and promoter hypermethylation could be attributed to silencing of DAPK1 gene expression in breast cancer. Thus, we consider DAPK1 inactivation by promoter hypermethylation likely plays a role in the development and progression of breast cancer.
\end{abstract}

Keywords: Breast cancer- DAPK1- hypermethylation- immunohistochemistry- MSP

Asian Pac J Cancer Prev, 20 (3), 839-848

\section{Introduction}

Breast cancer is one of the most common malignancies in women and is considered a genetic disease. Worldwide, there were an estimated 2.1 million cases and 626,679 deaths in 2018 (Bray et al., 2018). In the last few years, breast cancer has been rising progressively, and has now become the most common cancer in women in India with an estimated 1,62,468 incidences and 87,090 mortalities due to breast cancer in 2018 (Cancerindia.org.in, 2018). India has the maximum number of mortalities due to breast cancer than any other country in the world. The reason for this high mortality rate in India is the late detection of breast cancer. Thus, regardless of vast improvement in the overall prognosis and survival rate of patients with noninvasive breast cancer, advanced metastatic breast carcinoma remains a life-threatening disease. One of the major challenges in breast cancer research is now to identify clinically relevant and easily measurable key proteins modulating tumor progression in breast tumors, which can serve as early detection markers for invasive tumors as well as new drug targets. Alteration in expression of key genes through aberrant epigenetic regulation is one of the earliest and most frequent event in tumorigenesis and can contribute to the carcinogenesis and development of breast cancer (Baylin and Ohm, 2006). Epigenetic silencing of different types of genes occurs, including tumor suppressor genes (TSG), DNA repair genes, proapoptotic genes that suppress invasion and metastasis as a result, most of the important cellular network are negatively affected (Jovanovic et al., 2010). Therefore, it has been intensively attempted to exploit the tumor-associated DNA methylation pattern of TSGs for better cancer detection (Gheibi et al., 2012; Sturgeon et al., 2012). Furthermore, in contrast to genetic mutations, an important characteristic of epigenetic modifications such

${ }^{1}$ Department of Biotechnology, School of Life Sciences, Central University of Kashmir, ${ }^{3}$ Department of General Surgery, ${ }^{4}$ Departmet of Medical Oncology, Sher-I-Kashmir, Institute of Medical Sciences, Soura Srinagar, J and K, India, ${ }^{2}$ Clarke H. Smith Brain Tumour Centre, Arnie Charbonneau Cancer Institute, Cumming School of Medicine, University of Calgary, Calgary Alberta, Canada.*For Correspondence: mazargar65@gmail.com 
as DNA methylation is that they are potentially reversible and therefore, represent very promising therapeutic targets for breast cancer treatment.

Death-associated protein kinase-1 (DAPK-1) located on chromosome 9q21.33, is an actin associated calcium/ calmodulin-dependent enzyme with serine/threonine kinase activity (Cohen et al., 1997). DAPK-1 is mediator of tumor necrosis factor- $\alpha$, CD95 (Fas), and transforming growth factor- $\beta$-induced apoptosis, and has been demonstrated to be an essential mediator in interferon- $\gamma$-mediated programmed cell death (Cohen et al., 1999). Furthermore, it suppresses early stage oncogenic transformation by p19ARF-dependent activation of p53 thereby providing an intrinsic p53 dependent apoptotic check (Raveh et al., 2001). As disruption of processes involved in programmed cell death is a common feature of human cancers, it is significant that inactivation of DAPK-1 by hypermethylation has been described in a wide range of cancer cells compared with normal tissues, including lung (Zochbauerr-Muller et al., 2001), head and neck (Rosas et al., 2001), kidney and bladder (Christoph et al., 2006), cervical (Zhao et al., 2008), esophageal (Brock et al., 2003), B cell (Katzenellenbogen et al., 1999) and breast malignancies (Lehmann et al., 2002; Dulaimi et al., 2004; Tan et al., 2012). DAPK-1 suppresses tumor growth and metastasis by increasing the occurrence of apoptosis in vivo (Inbal et al., 1997). Loss of DAPK-1 expression has been reported to correlate strongly with more aggressive phenotype and poor overall survival rates of several types of human cancer, such as small cell lung cancer, primary head and neck tumors, colon and bladder cancer, multiple myeloma and breast cancer (Gozuacik and Kimchi, 2006).

In the present study, we addressed the role of DAPK-1 promoter methylation in the development of human breast cancer in ethnic Kashmiri population. Our next aim was to demonstrate a correlation between DAPK-1 promoter methylation and loss of protein expression in invasive ductal carcinoma (IDC) subtype of breast cancer that accounts for about $75-80 \%$ of all breast tumors worldwide. Finally, we aimed to analyze statistical correlations between clinicopathological patient characteristics, DAPK-1 methylation and its expression data.

\section{Materials and Methods}

\section{Patients}

Breast tissue samples $(\mathrm{n}=128)$ used for methylation and protein expression analyses were obtained from patients treated by primary surgery for breast cancer in the Department of General Surgery, Sher-I-Kashsmir Institute of Medical Sciences (SKIMS) as per the inclusion and exclusion criteria discussed below.

\section{Inclusion Criteria}

The main study inclusion criteria were:

- Histologically confirmed Breast Cancer patients undergone mastectomy.

- Patients who signed the appropriate informed consent form in accordance with local ethical committee guidelines.

\section{Exclusion Criteria}

- A history of significant or serious uncontrolled cardiovascular disease.

- Patients unwilling or unable to comply with the protocol.

- Patients with a history of another primary malignancy that was clinically significant or required active intervention.

All patients were recruited after histopathological diagnosis of breast cancer and all were females. All patients gave informed consent to the study for retention and analysis of their tissue for research purposes approved by the SKIMS Ethical Committee (registration no. SIMS1 31/IEC-SKIMS/2012-6339). Part of the tumour material and macroscopically normal breast (from tissues located at least $3 \mathrm{~cm}$ away from the site at which the tumor was sampled) were immediately shock-frozen after surgical resection and stored at $-80^{\circ} \mathrm{C}$ in deep freezer until further analysis. Hematoxylin and eosin (HandE)-stained sections were prepared for assessment of the percentage of tumour cells, only samples with $>80 \%$ tumour cells were selected. The normal breast tissue used for standardisation contained approximately $40 \%$ of epithelial cells. Histopathological staging was performed according to AJCC-02 TNM staging system and grading was carried out by surgeon according to the Scarff-Bloom- Richardson classification as GI, GII and GIII.

The questionnaire used in the study was well designed to get the finest of the details which were considered to have some relation with our study. Detailed information regarding the patient's medical history was collected from the hospital records of the patient. The questionnaire collected the information on; Clinico-epidemiological characteristics such as age, dwelling, family story of disease, body mass, menopause status, age at menarche, parity, site of tumor, marital status etc.

\section{DNA isolation}

Genomic DNA was isolated from tissue samples using proteinase $\mathrm{K}$ digestion and organic extractions according to standard procedures. Isolated DNA was resuspended in Tris EDTA buffer (pH 8.0) and stored at $-20^{\circ} \mathrm{C}$ until use. The integrity of the resulting genomic DNA was assessed by low percentage agarose gel electrophoresis and concentration was determined by UV spectrophotometer.

\section{Methylation-specific PCR (MSP)}

For detection of promoter methylation status, MSP was performed as described earlier (Asiaf et al., 2015; Asiaf et al., 2014). Briefly, extracted DNA was subjected to sodium bisulfite modification using EZ DNA Methylation $^{\mathrm{TM}}$ Kit (Zymo Research, USA) according to manufactures protocol. Modified DNA was subjected to MSP using specific primers for methylated sequences (sense 5'-GGATAGTCGGATCGAGTTAACGTC-3' and antisense 5'-CCCTCCCAAACGCCGA- 3') and for unmethylated sequences (sense 5'GGATAGTTGGATTGAGTTAATGTC -3' and antisense 5' - CAAАТCCСТCCCAAACACCAA-3'), which generates polymerase chain reaction $(\mathrm{PCR})$ products of 98 and $106 \mathrm{bp}$, respectively. The total $25 \mathrm{ml}$ of PCR 
mix contained $2 \mathrm{ml}$ of bisulfite-modified DNA, 1X PCR buffer, $2 \mathrm{mM} \mathrm{MgCl}$, 200ng of each primer, $0.3 \mathrm{mM}$ dNTPs (Fermentas life sciences, Inc. USA), and 1U of Taq polymerase (Fermentas life sciences, Inc. USA). PCR was carried out in Thermal cycler (Mastercycle, Ependroff) under the following conditions: $95^{\circ} \mathrm{C}$ for $10 \mathrm{~min}$, followed by 35 cycles of $95^{\circ} \mathrm{C}$ for $1 \mathrm{~min}, 64^{\circ} \mathrm{C}$ for $30 \mathrm{sec}, 72^{\circ} \mathrm{C}$ for $1 \mathrm{~min}$ a final extension at $72^{\circ} \mathrm{C}$ for 10. From each PCR reaction, $8 \mu \mathrm{l}$ was loaded onto a $3 \%$ agarose gel, stained with ethidium bromide and visualized under UV illumination and photographed with Alpha Imager 1,220 v5.5 Camera software. Representative gel pictures are shown in Figure1. The PCR for all samples demonstrating methylation for the individual genes was repeated to confirm these results.

Water blanks were used as a negative control for methylated genes. DNA from peripheral blood lymphocytes of healthy volunteers treated with SssI methyltransferase (New England Biolabs, Beverly, MA, USA) and then subjected to bisulfite modification was used as positive controls for methylated alleles. The reaction was performed in a total volume of 50 $\mu \mathrm{l}$ containing $10 \mu \mathrm{g}$ of genomic DNA, $10 \mathrm{U}$ of SssI methylase, $160 \mathrm{mM}$ of S-adenosyl-methionine, $50 \mathrm{mM}$ of $\mathrm{NaCl}, 10 \mathrm{mM}$ of Tris-HCl, $10 \mathrm{mM}$ of $\mathrm{MgCl}_{2}, 1 \mathrm{mM}$ of DTT pH 7.9, during 18 hours at $37^{\circ} \mathrm{C}$.

\section{Immunohistochemistry}

Sections of formalin-fixed, paraffin-embedded breast were obtained on polyl-lysine coated slides. Sections were dewaxed in xylene and rehydrated by descending concentrations of ethanol. Slices were subjected to antigen retrieval using microwave heating (20 minutes, citrate buffer $\mathrm{pH}, 6.0,10 \mathrm{mM}$ ) at $95^{\circ} \mathrm{C}$ followed by incubation with specific primary antibodies recognizing estrogen receptor (ER) (dilution 1:100; Santacruz Biotechnology Inc., USA), the progesterone receptor (PgR) (1:100 dilution, clone 1A6, Biocare Medical, USA), Her2/ neu (sc-08, dilution 1:100; Santacruz Biotechnology Inc., USA) and DAPK-1 (EPR1818(2) dilution 1:200 dilution Abcam) under humid conditions overnight at $4{ }^{\circ} \mathrm{C}$. Endogenous peroxidase activity was blocked with $3 \% \mathrm{H}_{2} \mathrm{O}_{2}$ for $30 \mathrm{~min}$. Antibodies used in this study were validated (Supplentary file 1).

Next day, the slides were washed three times in Tris buffers ( $\mathrm{pH}$ 6.0) and bound primary antibody was detected by MACH1 Universal HRP-Polymer (Biocare medical, USA) for $30 \mathrm{~min}$ at room temperature. After washing in Tris buffer, the immunostaining reaction product was developed using 3,3-diaminobenzidine (Betazoid DAB Plus substrate, Biocare Medical, USA). After immunoreactivity, slides were dipped in distilled water, counterstained with Harris hematoxyline and finally the sections were dehydrated in xylene, mounted with DPX and coverslipped.

In all cases, adjacent normal surrounding tissue served as an internal positive control. In negative controls, the primary antibody was replaced by non-immune mouse IgG of the same isotype to ensure specificity.

Tumors were classified by intensity of staining and the percentage of cells showing antibody reactivity. The ER and PR sections were scored for the immunohistochemical signal as follows: weak $(1+)$, moderate $(2+)$, and strong (3+) staining in $>10 \%$ of the tumor cells or absent ( 0 ). Positivity nuclear staining was defined as moderate/strong expression $(2+, 3+)$ in nucleus. For Her2/neu protein expression, membrane immunostaining was considered as positive. Briefly, the scoring system was as follows: no staining or membrane staining in fewer than $10 \%$ of tumor cells, 0 ; faint, barely perceptible membrane staining in more than $10 \%$ of tumor cells, the cells are stained only in part of the membrane, $1+$; weak to moderate complete membrane staining observed in more than $10 \%$ of tumor cells, 2+; and strong, complete membrane staining in more than $10 \%$ of tumor cells, $3+$ (Rhodes et al., 2002). For DAPK-1 protein expression, the slides were scored numerically by the pathologist on intensity of DAPK-1 cytoplasmic staining (SI; 1 = weak, 2 = moderate, $3=$ strong) and the percentage of positive cells (PC; $1=<$ $10 \%, 2=10-50 \%, 3=51-80 \%, 4=>80 \%)$. The product of the two values would result in a composite DAPK-1 score, and the scores were stratified as low $=0-3$, intermediate $=4-8$, and high $=9-12$ (Kuester et al., 2007). For all statistical analyses, the samples were grouped into either DAPK-1 low (0-3) or DAPK-1 medium/high (4, 6, 8,9 , and 12) groups.

\section{Western blotting}

Total protein extracts from 56 frozen breast cancer and adjacent normal samples were prepared with lysis buffer (50 mM Tris- $\mathrm{HCl}, 0.3 \mathrm{M} \mathrm{NaCl}, 1 \mathrm{mM}$ EDTA and $1 \mathrm{mM}$ dithiothreitol) supplemented with a cocktail of protease inhibitors (Sigma Aldrich, USA). Protein extracts were resolved on SDS-polyacrylamide gels and subsequently electrotransferred onto nitrocellulose membranes (Invitrogen, USA).) in trans-buffer (25 mM Tris; $129 \mathrm{mM}$ glycine; $10 \%$ methanol; $0.05 \%$ SDS). Membranes were blocked in 5\% non-fat milk in $1 \%$ TBST for $1 \mathrm{~h}$ at room temperature, and incubated overnight at $4{ }^{\circ} \mathrm{C}$ with a rabbit anti-DAPK1 monoclonal antibody (Abcam, USA) diluted in the same blocking buffer. After washing, membranes were incubated with goat anti-rabbit (Abcam, USA) antibodies conjugated to horseradish peroxidase. Blots were developed with Super Signal chemiluminescence reagent (Pierce). For loading control, membranes were stripped and reprobed with a human-specific antibody against $\beta$-actin (Sigma Aldrich, USA). We calculated the DAPK1 protein expression in tumor tissues by normalisation with the corresponding normal tissue lysate taken as 1.0 .

\section{Statistical analysis}

The association of gene methylation and DAPK-1 scores with clinical pathological variables was statistically tested using the exact Pearson Chi-squared test. The logistic regression model was used to assess univariate association between DAPK-1 scores (low vs. medium/ high), DAPK-1 methylation status (methylated vs. unmethylated) and clinical pathological variables. The variables that were significantly associated with DAPK-1 scores in univariate analysis were then simultaneously put in multivariate logistic regression model to assess

Asian Pacific Journal of Cancer Prevention, Vol $20 \quad \mathbf{8 4 1}$ 
the association while adjusting for other significantly associated variables. All $\mathrm{p}$ values are two-sided and considered statistically significant at the 0.05 level. All statistical analyses were performed using SPSS (version 16s; SAS Institute; Cary, NC, USA).

\section{Results}

Clinicopathological findings

A total of 128 cases of IDC were included in this study. The mean age of patients was $51.85 \pm 1.02$ years and median age was 53 (range 26-80). The mean body mass index (BMI) was 23.64 \pm 0.21 . Age was grouped into two categories with $56.2 \%$ of cases lying in the group $>50$ years of age. Approximately $68.0 \%$ were rural. The stage distribution was typical with $38.3,31.3,23.4$ and $7.0 \%$ presenting with Stage I, II, III, and IV respectively. Stage III and IV were combined for all statistical analysis. Most of the tumors were ER-positive (69.5\%) and PR positive (66.4\%). Her-2-neu immunostaining was detected in only $25 \%$ of breast tumors (Table 1 ).

\section{Methylation Analysis of DAPK-1}

We utilized MS-PCR method to analyze genomic DNA (gDNA) from fresh frozen tissues from patients with invasive ductal carcinoma and normal breast tissue adjacent to tumor for DAPK1 promoter methylation. Representative results for MSP analysis are demonstrated in Figure 1. MSP showed that 37 (29\%) of 128 breast tumors were hypermethylated in the DAPK1 promoter region. Accordingly, $71 \%$ of the breast cancer specimens $(91 / 128)$ exhibited no DAPK1 promoter methylation. On the otherhand, hypermethylation of DAPK1 promoter region was observed in $6(4.6 \%)$ of 128 adjacent normal breast tissues. There was a significant difference in the methylation frequency DAPK1 between tumor and normal samples. In all the methylated samples, both unmethylated and methylated PCR products were detected suggesting monoallelic DAPK promoter hypermethylation. Biallelic methylation was not observed in any of the methylated samples.

Epigenetic silencing of DAPK1 protein expression in Breast Cancer

Immunohistochemical analysis of DAPK1 was carried out to determine the effect of promoter methylation on gene silencing and consequent loss of protein expression.

Table1. Clinical and Pathological Characteristics of the Patient Population

\begin{tabular}{|c|c|}
\hline Patients & 128 \\
\hline Age(years), mean \pm SEM & $51.85 \pm 1.06$ \\
\hline$\leq 50$ & $56(43.8)$ \\
\hline$>50$ & $72(56.2)$ \\
\hline \multicolumn{2}{|l|}{ Menopausal status } \\
\hline Premenopausal & $78(60.9)$ \\
\hline Postmenopausal & $50(39.1)$ \\
\hline \multicolumn{2}{|l|}{ Nodal status } \\
\hline Negative & $79(61.7)$ \\
\hline Positive & $49(38.3)$ \\
\hline BMI & $23.64 \pm 0.21$ \\
\hline$\leq 24.9$ & $67(52.3)$ \\
\hline $25-29.9$ & $37(28.9)$ \\
\hline$\geq 30$ & $24(18.8)$ \\
\hline \multicolumn{2}{|l|}{ Grade } \\
\hline I & $29(22.6)$ \\
\hline II & $79(61.7)$ \\
\hline III & $20(15.6)$ \\
\hline \multicolumn{2}{|l|}{ Stage } \\
\hline I & $49(38.3)$ \\
\hline II & $40(31.3)$ \\
\hline III & $30(23.4)$ \\
\hline IV & $9(7.0)$ \\
\hline \multicolumn{2}{|l|}{ Dwelling } \\
\hline Rural & $87(68.0)$ \\
\hline Urban & $41(32.0)$ \\
\hline \multicolumn{2}{|l|}{ Tumor size } \\
\hline$\leq 2.0 \mathrm{~cm}$ & $22(17.2)$ \\
\hline $2.1-4.9 \mathrm{~cm}$ & $59(46.1)$ \\
\hline$\geq 5 \mathrm{~cm}$ & $47(36.7)$ \\
\hline \multicolumn{2}{|l|}{ ER-receptor } \\
\hline Positive & $89(69.5)$ \\
\hline Negative & $39(30.5)$ \\
\hline \multicolumn{2}{|l|}{ PR-receptor } \\
\hline Positive & $85(66.4)$ \\
\hline Negative & $43(33.6)$ \\
\hline \multicolumn{2}{|l|}{ Her-2-neu } \\
\hline Positive & $32(25)$ \\
\hline Negative & $96(75)$ \\
\hline
\end{tabular}

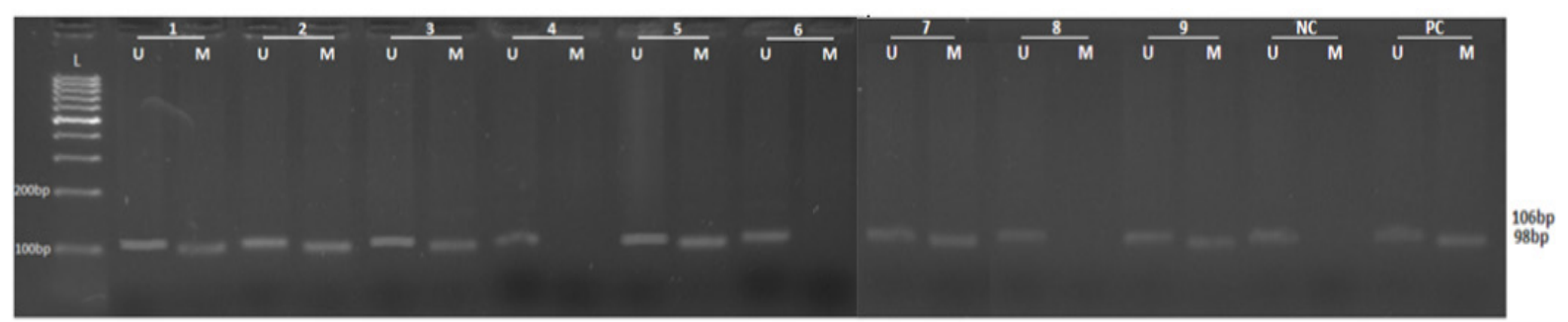

Figure 1. MSP Analysis of DAPK1 Gene in Breast Cancer Tissues. Existence of PCR products in lane M indicates the presence of methylation. MSP product in lane U indicates the presence of nonmethylation alleles. In vitro SssI methyltransferase-treated and -untreated DNA from normal lymphocytes were used as the positive controls (PC) for methylation and nonmethylation (NC), respectively. L, 100-bp DNA marker ladder; The methylated allele was detected in Cases 1-3, 5, 7 and 8. Unmethylated allele was detected in Cases 4, 6 and 9. 


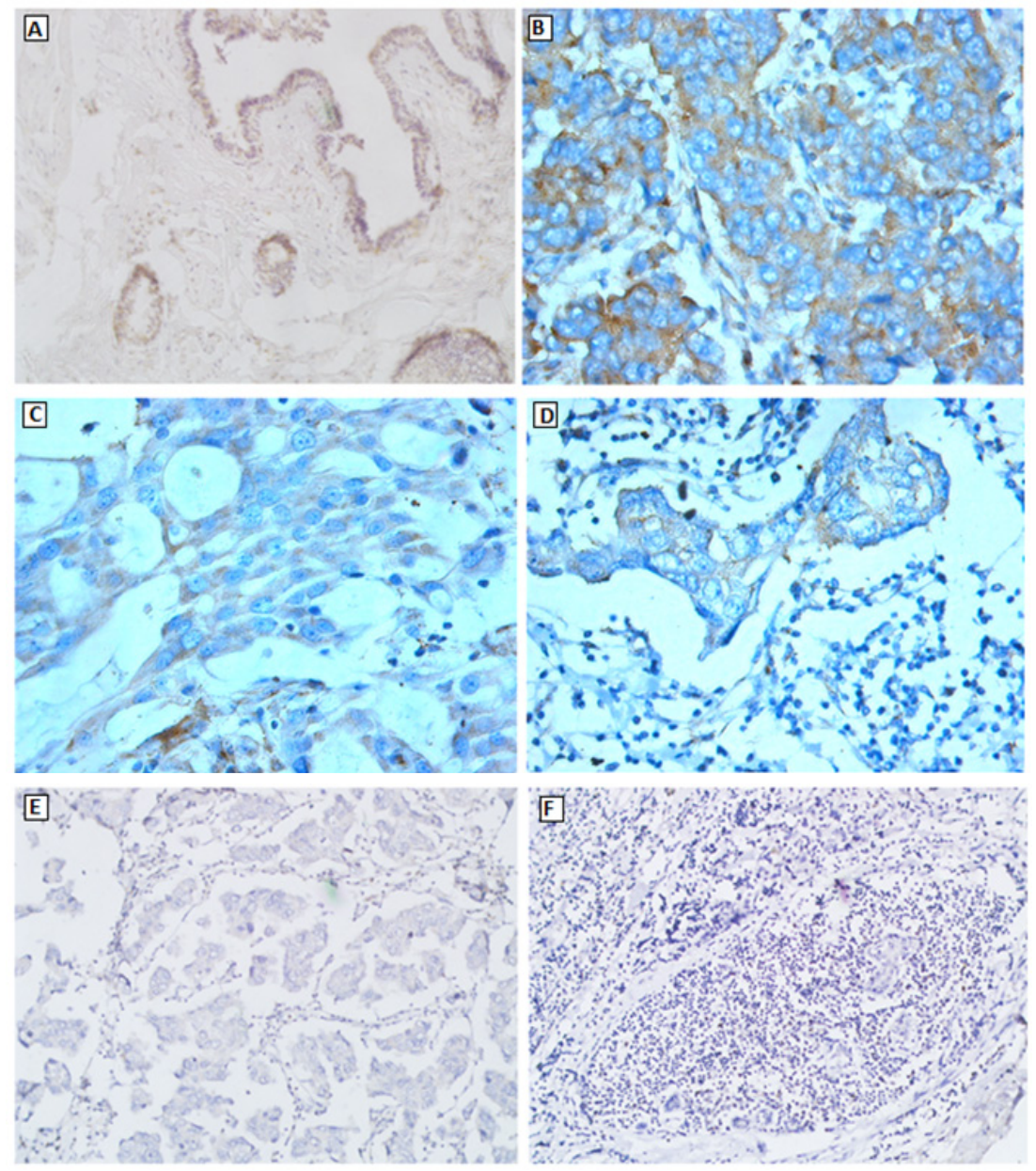

Figure 2. Representative Immunostaining Photographs of DAPK in Mammary Gland. Positive staining was identified by the presence of brown staining in the cytoplasm. Cytoplasmic expression of DAPK was observed in normal breast (A), with variable expression in IDCs ranging from strong (IHC score 9-12) (A), intermediate (IHC score 4-8) (B), low (IHC score 0-3) (C) or completely absent (D). Negative control (E) (original magnification- X20).

Normal breast tissue exhibited positive immunostaining for DAPK1 protein in ductal epithelial cells. Out of 128 tumor samples, 45 (35.2\%), 42 (32.8\%), and $41(32.0 \%)$ had a low, medium, and high DAPK1 score, respectively (Figure 2). Comparison of methylation and Immunohistochemistry data revealed that out of 37 cases exhibiting methylation in DAPK1, 23 (62.2\%) showed loss or weak cytoplasmic immunoreactivity for DAPK1 protein. In contrast, in unmethylated group, cytoplasmatic staining with moderate to strong intensity of immunoreactivity was observed in $69(75.8 \%)$ while 22 (24.2\%) showed reduced or loss of expression of DAPK1 protein. There was a significant inverse correlation between DAPK1 promoter hypermethylation and loss of its protein $(\mathrm{rs}=-0.361, \mathrm{p}<0.001)$ (Table 2$)$.

Correlation analysis between DAPK-1 methylation and clinicopathological parameters of breast cancer

Statistical analysis of the correlation of methylation status with clinical and demographic characteristics revealed no significant correlations for the frequency of DAPK1 hypermethylation with menopausal status, dwelling, BMI and tumor grading. A hypermethylated DAPK1 promoter was significantly associated with age at diagnosis $(\mathrm{OR}=2.31, \mathrm{CI}: 1.02-5.23, \mathrm{p}=0.041)$ and tumor stage $(p=0.033)$. Univariate analysis for DAPK1 hypermethylation between tumor stages demonstrated stage II with an $\mathrm{OR}=1.69(\mathrm{CI}: 0.62-4.60, \mathrm{p}=0.305)$ and Stage IIIand IV with an OR=3.43 (CI: $1.31-8.98, \mathrm{p}=0.01$ ) in comparison to stage I. We did not find an association between DAPK1 methylation and the tumor PR or HER2 status. Estrogen-receptor-negative tumors were associated with higher promoter methylation compared to estrogen-receptor- positive tumors $(\mathrm{OR}=3.16, \mathrm{CI}$ : 1.41-7.09, $\mathrm{p}=0.004)$. Similarly, DAPK1 methylation in breast cancer was strongly associated with triple- negative breast cancers (ER-, PR- and Her2/neu-concomitant triple negative) $(\mathrm{O} . \mathrm{R} .=4.39$, C.I. $=1.60-121.07, \mathrm{p}=0.003)$.

Table 2. Correlation between DAPK Methylation and DAPK Expression in Breast Cancer Tissue Samples

\begin{tabular}{lcccccc}
\hline Gene & Loss of expression & Normal expression & OR & CI (95\%) & Pvalue & rs \\
\hline DAPK methylated & $23(62.2)$ & $14(37.8)$ & 5.15 & $2.27-11.69$ & $<0.001$ & -0.361 \\
DAPK unmethylated & $22(24.2)$ & $69(75.8)$ & 1.0 (reference) & & & \\
\hline
\end{tabular}

OR odds ratio at $95 \%$ confidence interval $(95 \% \mathrm{CI})$; p value from $\chi^{2}$ test; rs Spearman's co-efficient 
Table 3. Univariate Logistic Regression for Promoter Methylation Status- Unmethylated (Reference) versus Methylated

\begin{tabular}{|c|c|c|c|c|c|}
\hline \multirow[t]{2}{*}{ Variable } & \multicolumn{2}{|c|}{ DAPK1 methylation } & \multirow[t]{2}{*}{$\mathrm{OR}(\mathrm{CI})$} & \multirow[t]{2}{*}{$P$ value (1) } & \multirow[t]{2}{*}{$P$ value $(2)$} \\
\hline & Presence N (\%) & Absence N (\%) & & & \\
\hline \multicolumn{6}{|l|}{ Age } \\
\hline$\leq 50$ & $11(28.6)$ & 45 (71.4) & 1 (reference) & 0.041 & 0.041 \\
\hline$>50$ & $26(29.2)$ & $46(70.8)$ & $2.31(1.02-5.23)$ & & \\
\hline Menopausal status & $23(29.5)$ & $55(70.5)$ & 1 (reference) & 0.862 & 0.862 \\
\hline Postmenopausal Premenopausal & $14(28.0)$ & $36(72.0)$ & $0.93(0.43-2.04)$ & & \\
\hline \multicolumn{6}{|l|}{ Nodal status } \\
\hline Negative & $18(20.3)$ & $61(79.7)$ & 1 (reference) & 0.052 & 0.052 \\
\hline Positive & $19(42.9)$ & $30(57.1)$ & $2.15(0.99-4.68)$ & & \\
\hline \multicolumn{6}{|l|}{ BMI } \\
\hline$\leq 24.9$ & $20(29.9)$ & $47(70.1)$ & 1 (reference) & - & \\
\hline $25-29.9$ & $10(27.0)$ & $27(73.0)$ & $0.87(0.36-2.13)$ & 0.761 & 0.954 \\
\hline$\geq 30$ & $7(29.2)$ & $17(70.8)$ & $0.97(0.35-2.69)$ & 0.95 & \\
\hline \multicolumn{6}{|l|}{ Tumor stage } \\
\hline I & $9(24.5)$ & $40(75.5)$ & 1(reference) & - & \\
\hline II & $11(35.0)$ & $29(65.0)$ & $1.69(0.62-4.60)$ & 0.305 & 0.033 \\
\hline III and IV & $17(28.2)$ & $22(71.8)$ & $3.43(1.31-8.98)$ & 0.01 & \\
\hline \multicolumn{6}{|l|}{ Tumor Grade } \\
\hline $\mathrm{I}$ & $4(13.8)$ & $25(86.2)$ & 1(reference) & - & \\
\hline II & $28(35.4)$ & $51(64.6)$ & $3.43(1.09-10.86)$ & 0.036 & 0.082 \\
\hline III & $5(25.0)$ & $15(75.0)$ & $2.08(0.483-8.99)$ & 0.325 & \\
\hline \multicolumn{6}{|l|}{ Dwelling } \\
\hline Urban & $9(22.0)$ & $32(78.0)$ & 1 (reference) & 0.233 & 0.233 \\
\hline Rural & $28(32.2)$ & $59(67.8)$ & $1.69(0.71-4.01)$ & & \\
\hline \multicolumn{6}{|l|}{ Estrogen receptor } \\
\hline Positive & $19(21.3)$ & $70(78.7)$ & 1 (reference) & & \\
\hline Negative & $18(46.2)$ & $21(53.8)$ & $3.16(1.41-7.09)$ & 0.004 & 0.004 \\
\hline \multicolumn{6}{|l|}{ Progesterone receptor } \\
\hline Positive & $20(23.5)$ & $65(76.5)$ & 1 (reference) & & \\
\hline Negative & $17(39.5)$ & $26(60.5)$ & $2.13(0.96-4.69)$ & 0.059 & 0.059 \\
\hline \multicolumn{6}{|l|}{ Her-2-neu } \\
\hline Positive & $11(34.4)$ & $21(65.6)$ & 1 (reference) & & \\
\hline Negative & $26(27.1)$ & $70(72.9)$ & $0.71(0.30-1.67)$ & 0.431 & 0.431 \\
\hline \multicolumn{6}{|l|}{$\mathrm{ER} \alpha / \mathrm{PR} /$ Her-2-neu status } \\
\hline Positive * & $26(23.9)$ & $83(76.1)$ & 1 (reference) & 0.003 & 0.003 \\
\hline Negative** & $11(57.9)$ & $8(42.1)$ & $4.39(1.60-12.07)$ & & \\
\hline
\end{tabular}
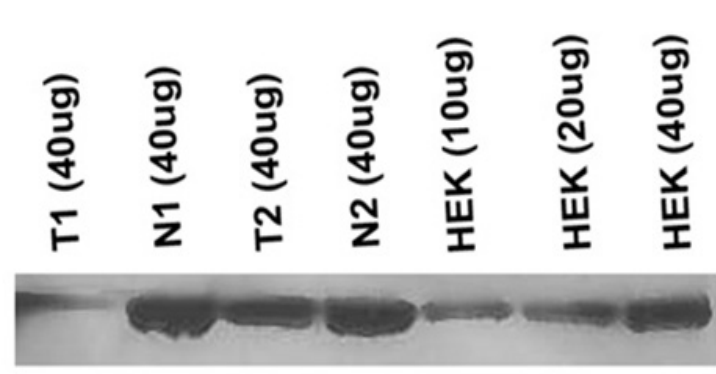

\section{Ab. DAPK1}

Figure 3. The Representative Western Blot Shows the Expression of DAPK1 Protein Using the DAPK1 Antibody. Lane 1: (T1) Breast tumor tissue lysate $(40 \mu \mathrm{g})$, lane 2: (N1) Normal breast tissue lysate $(40 \mu \mathrm{g})$, lane 3: (T2) Breast tumor tissue lysate $(40 \mu \mathrm{g})$ lane 4: (N2) Normal breast tissue lysate $(40 \mu \mathrm{g})$, lane 5: pB513B1-DAPK1 transfected HEK cell lysate $(10 \mu \mathrm{g})$, lane 6: pB513B1-DAPK1 transfected HEK cell lysate $(20 \mu \mathrm{g})$, lane 73:pB513B1-DAPK1 transfected HEK cell lysate $(40 \mu \mathrm{g})$, 
Besides, a marginal correlation of DAPK1 promoter hypermethylation with nodal involvement was observed $(p=0.052)$ (Table 3$)$.

Association of DAPK protein expression with clinicopathological parameters

The association between the expression level of DAPK1 and clinicopatholigical characteristics were parallel to those observed with DAPK1 methylation. Tumors with low or no DAPK1 protein expression showed significant correlation with ER and ER/PR/Her2/neu negativity $(\mathrm{p}=0.003, \mathrm{O} . R .=3.16$, C.I. $=1.44-6.92 ; \mathrm{p}=0.024$, O.R. $=3.03$, C.I. $=1.12-8.22)$ respectively. Univariate
Epigenetic Inactivation of DAPK1 in Breast Cancer

analysis for low DAPK1 expression between breast tumor stages demonstrated stage II tumors with an OR = $3.79(1.42-10.13, \mathrm{p}=0.008)$ and stage III andIV tumors with an OR $=5.40(2.02-14.43, \mathrm{p}=0.001)$ compared to stage I tumors. There were no significant correlations of immunohistochemically estimated DAPK1 protein expression with menopausal status, age, dwelling, BMI, tumor differentiation, and lymph node metastasis (Table 4. In the multivariate analysis (Table 5), low or no expression of DAPK1 was found to be associated with advanced tumor stage $(p=0.005)$ only and not with ER negativity $(\mathrm{p}=0.092)$ and triple negative breast cancer $(\mathrm{p}=0.589)$.

Expression of DAPK1 in Breast tissues using western

Table 4. Univariate Logistic Regression for DAPK Expression- Low versus Normal (Reference)

\begin{tabular}{|c|c|c|c|c|c|}
\hline \multirow{2}{*}{$\begin{array}{l}\text { Variable } \\
\text { Age }\end{array}$} & \multicolumn{2}{|c|}{ Normal Low } & \multirow[t]{2}{*}{ OR $(95 \% \mathrm{CI})$} & \multirow[t]{2}{*}{$\mathrm{P}$ value (1) } & \multirow[t]{2}{*}{ P value (2) } \\
\hline & & & & & \\
\hline$\leq 50$ & $37(66.1)$ & $19(33.9)$ & 1 (reference) & & \\
\hline$>50$ & 46 (63.9) & $26(36.1)$ & $1.10(0.53-2.30)$ & 0.798 & 0.798 \\
\hline \multicolumn{6}{|l|}{ Menopausal status } \\
\hline Postmenopausal & $52(66.7)$ & $26(33.3)$ & 1 (reference) & & \\
\hline Premenopausal & $31(62.0)$ & $19(38.0)$ & $0.82(0.39-1.71)$ & 0.59 & 0.59 \\
\hline \multicolumn{6}{|l|}{ Nodal status } \\
\hline Negative & $55(69.6)$ & $24(30.4)$ & 1 (reference) & 0.151 & 0.151 \\
\hline Positive & $28(57.1)$ & $21(42.9)$ & $1.72(0.82-3.61)$ & & \\
\hline \multicolumn{6}{|l|}{ BMI } \\
\hline$\leq 24.9$ & $39(58.2)$ & $28(41.8)$ & 1 (reference) & - & \\
\hline $25-29.9$ & $25(67.6)$ & $12(32.4)$ & $0.67(0.29-1.55)$ & 0.349 & 0.167 \\
\hline$\geq 30$ & $19(79.2)$ & $5(20.8)$ & $0.37(0.12-1.10)$ & 0.073 & \\
\hline \multicolumn{6}{|l|}{ Tumor stage } \\
\hline I & $41(83.7)$ & $8(16.3)$ & 1 (reference) & - & \\
\hline II & $23(57.5)$ & $17(42.5)$ & $3.79(1.42-10.13)$ & 0.008 & 0.001 \\
\hline III and IV & $19(48.7)$ & $20(51.3)$ & $5.40(2.02-14.43)$ & 0.001 & \\
\hline \multicolumn{6}{|l|}{ Tumor Grade } \\
\hline I & $20(69.0)$ & $9(31.0)$ & 1(reference) & - & \\
\hline II & $46(58.2)$ & $33(41.8)$ & $1.59(0.65-3.94)$ & 0.312 & 0.071 \\
\hline III & $17(85.0)$ & $3(15.0)$ & $0.39(0.09-1.69)$ & 0.208 & \\
\hline \multicolumn{6}{|l|}{ Dwelling } \\
\hline Urban & $28(68.3)$ & $13(31.7)$ & 1(reference) & 0.575 & 0.575 \\
\hline Rural & $55(63.2)$ & $32(36.8)$ & $1.25(0.57-2.76)$ & & \\
\hline \multicolumn{6}{|l|}{ Estrogen receptor } \\
\hline Positive & $65(73.0)$ & $24(27.0)$ & 1 (reference) & & \\
\hline Negative & $18(46.2)$ & $21(53.8)$ & $3.16(1.44-6.92)$ & 0.003 & 0.003 \\
\hline \multicolumn{6}{|c|}{ Progesterone receptor } \\
\hline Positive & $60(70.6)$ & $25(29.4)$ & 1 (reference) & 0.56 & 0.56 \\
\hline Negative & $23(53.5)$ & $20(46.5)$ & $2.09(0.98-4.46)$ & & \\
\hline \multicolumn{6}{|l|}{ Her-2-neu } \\
\hline Positive & $22(68.8)$ & $10(31.2)$ & 1(reference) & 0.593 & 0.593 \\
\hline Negative & $61(63.5)$ & $35(36.5)$ & $1.26(0.54-2.97)$ & & \\
\hline \multicolumn{6}{|c|}{ ER/PR/Her-2-neu status } \\
\hline Positive* & $75(68.8)$ & $34(31.2)$ & 1 (reference) & 0.024 & 0.024 \\
\hline Negative** & $8(42.1)$ & $11(57.9)$ & $3.03(1.12-8.22)$ & & \\
\hline
\end{tabular}

Bold values indicate statistical significance $\mathrm{p}<0.05$, OR odds ratio calculated at $95 \%$ confidence interval (95\% CI); (1) Specific level $\mathrm{p}$ value, (2) overall variable p value, $\mathrm{p}$ value (two-sided) Pearson's $\chi 2$ test ; *Positive for any of the 3 receptors (ER/PR/Her2); **, Triple negative Breast cancer. 


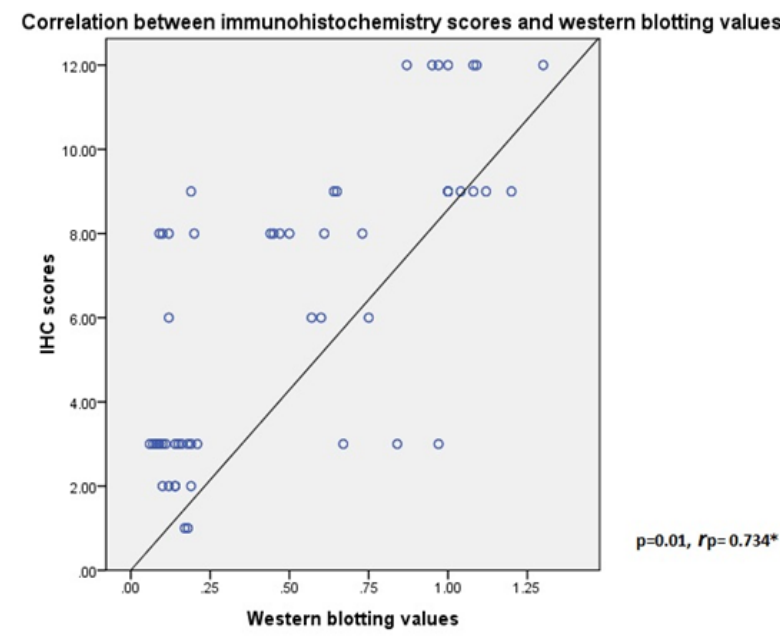

Figure 4. Relationship between Western Blotting Values and Immunohistochemical Expression Analysis of DAPK1 in IDCs of Breast Using Pearson Correlation Test.

\section{blotting}

We also examined DAPK1 expression by Western blotting in 56 frozen breast cancer and adjacent normal samples to confirm the results obtained by immunohistochemistry showing association between DAPK1 promoter methylation and its impaired synthesis. Among 56 IDC tumor tissues 23 were methylated and 33 were unmethylated. Out of 23 methylated tumors, 16 expressed loss or marked reduction of DAPK1 expression, whereas the remaining seven tumors expressed similar amounts of DAPK1 compared with their matching normal tissues. In contrast, 22 of the 33 unmethylated tumors expressed amounts of DAPK1 similar to those expressed by their corresponding normal tissues. Only 11 unmethylated tumors showed reduced expression of DAPK1 compared to their normal counterpart. Representative examples are shown in Figure 3. These results confirmed that hypermethylation of the $\mathrm{CpG}$ islands located in the promoter region of the DAPK1 gene is associated with loss of DAPK1 expression of protein in breast cancer tissues as observed by immunohistochemistry analysis. A significant positive correlation between the immunohistochemical results and the western blotting values for DAPK1 (Figure 4) was observed.

\section{Discussion}

DAPK1 has a critical role in regulating apoptosis under normal growth conditions that is highlighted by the fact that tumor cells utilize multiple mechanisms to evade DAPK1 mediated cell death, thus creating permissive environment for accumulation of genetic instabilities and promoting the initiation and progression of cancer. Thus, it becomes our ultimate goal to gain a deeper insight into the mechanisms involved in DAPK1 regulation, as this may assist in the design of suitable therapeutic regimens to enable the outcome of cell fate decisions in tumor cells to be tipped in favour of apoptosis.

An earlier investigation analysing DAPK1 methylation
Table 5. Multivariable Logistic Regression for DAPK Expression-Low (Reference) versus Medium/High

\begin{tabular}{|c|c|c|}
\hline Variable & OR (CI 95\%) & $P$ value \\
\hline \multicolumn{3}{|l|}{ Tumor Stage } \\
\hline I & 1 & 0.005 \\
\hline II & $3.35(1.22-9.21)$ & \\
\hline III \& IV & $5.27(1.92-14.46)$ & \\
\hline \multicolumn{3}{|c|}{ Estrogen receptor } \\
\hline Positive & 1 & 0.092 \\
\hline Negative & $2.46(0.86-7.03)$ & \\
\hline \multicolumn{3}{|c|}{ ER/PR/Her-2-neu status } \\
\hline Negative & 1 & 0.589 \\
\hline Positive & $1.45(0.38-5.53)$ & \\
\hline
\end{tabular}

in different histological subtypes of breast cancer, reported that, lobular invasive breast carcinomas exhibit a high level of DAPK1 loss of expression (mRNA) and promoter hypermethylation (53\%) whereas, only $9 \%$ of their 85 invasive ductal carcinoma specimens showed promoter hypermethylation (Lehmann et al., 2002). Another study analyzed methylation of DAPK1 in breast tumor and paired preoperative serum DNA and detected promoter hypermethylation in $40 \%$ of invasive ductal carcinoma breast tumor samples (Dulaimi et al., 2004). Furthermore, we demonstrated a significant difference in hypermethylation frequency between cancerous tissues and the corresponding normal breast tissues. These data collectively suggest that the methylation of DAPK1 promoter is a tumor-specific phenomenon. However, the presence of hypermethylation in some adjacent non-cancerous tissues represents field defect of premalignant changes that occurs early in carcinogenesis. The fact about the adjacent normal breast tissues that they lack microscopic evidence of malignancy suggests that these changes are not transforming themselves. However, they might allow the prospective acquisition and accumulation of other genetic and epigenetic changes that do, in time, lead to malignancy in spatio-temporal manner. Alternatively, there may be a threshold level for hypermethylation to affect protein expression of gene and lead to a growth advantage.

The methylation of $\mathrm{CpG}$ islands located within the promoter region is generally associated with a decrease in protein expression or a loss of protein expression (Baylln et al., 1997; Esteller, 2008). In fact, in this study, the occurrence of DAPK1 promoter hypermethylation correlated strongly with a marked decrease in protein expression suggesting that DNA hypermethylation may be the probable inactivation mechanism of this gene in breast tumors. However, a decreased DAPK1 immunostaining in $24.2 \%$ of cases without DAPK 1 methylation may be due to other mechanisms, such as gene mutation and loss of heterozygosity (LOH) or promoter homozygous deletions of $\mathrm{CpG}$ island which have also been shown to be involved in the regulation of DAPK1 expression in breast and other cancer as well (Simpson et al., 2002; Raveh and Kimchi, 2001). Furthermore, for some methylated cases, we 
observed a complete loss of DAPK1 protein expression, even though a biallelic methylation was ever obtained by MS-PCR. In these cases, accompanying unmethylated PCR products might be the result of contamination with inflammatory cells and surrounding stroma. To the best of our knowledge, this is the first comprehensive study reporting loss of DAPK1 protein expression associated with DAPK1 promoter methylation in invasive ductal carcinoma subtype of Kashmiri breast cancer patients.

The number of clearly different molecular phenotypes of breast tumors suggests that much is unknown regarding the diversity of these neoplasms. Triple-negative breast cancers (TNBC) represent $10-17 \%$ of all breast malignancies, occur in young women, and are associated with a high risk of early relapse and poor survival (Yuan et al., 2014). In our study, significant association was observed between loss of DAPK1 protein expression and ER negativity and triple negative phenotype. Although we did not perform a survival analysis in our patients, these findings demonstrate that loss of DAPK1 is associated with poor prognosis in breast cancer. However, this result warrants confirmation because the group of patients with triple negative phenotype was small $(\mathrm{n}=19)$, moreover, while loss of DAPK1 expression appeared to be associated with triple negative breast cancers in univariate analysis, this association could not be confirmed on the multivariate analysis and may require a larger dataset to evaluate this. Our data that loss of DAPK1 expression is associated with ER negativity and triple negative phenotype corroborate the earlier findings who also found either decreased expression or increased hypermethylation of DAPK1 in these phenotypes (Levy et al., 2004; Hafez et al., 2015).

Moreover, we found a significant positive correlation between DAPK1 methylation and age at diagnosis in our large cohort $(n=128)$ of breast cancer patients. Promoter methylation in several genes increases with age in normal tissues, although the exact impact of aging in methylation status remains unknown (Issa and Ahuja, 2000). In addition we could show a significantly higher DAPK1 promoter hypermethylation and weaker DAPK1 protein expression in tumor of higher stages relative to less advanced stage tumors. Similarly, higher hypermethylation of DAPK gene was observed in more advanced stage of cervical cancer (Narayan et al., 2003). This increased loss of protein expression with advanced tumor invasiveness and tumor stage supports the potential protective function of DAPK1 against tumor progression and metastasis in breast carcinogenesis. No further correlations between DAPK1 methylation and other clinicopathological parameters were found, except the marginal correlation with nodal status.

Based on the differences in the expression of DAPK1 between groups with distinct prognostic characteristics, we hypothesize that the immunohistochemical evaluation of this marker predicts tumor progression. However, additional studies that address these specific issues must be performed.

In conclusion, taken together, our analysis regarding aberrant DAPK-1 promoter methylation and DAPK-1 expression lead to the following conclusions: DAPK-1 is indeed a tumour suppressor gene in normal breast tissue, which undergoes epigenetical silencing during breast tumorigenesis. The methylation status of DAPK-1 predicts poor prognosis and could serve as a prognostic biomarker in human breast cancer. However, the clinical significance of our preliminary findings should be further confirmed in large cohorts that will undoubtedly lead to a greater understanding of breast cancer progression and may help to establish therapeutic strategies for patients with breast cancer.

\section{Conflict of interest}

All authors have read the journal's policy on authorship agreement and conflict of interest, and declared no conflict of interest.

\section{Acknowledgements}

The authors are thankful to the University Grants Commission (UGC), New Delhi, India, for providing the funds that allowed us to carry out this research.

\section{References}

Asiaf A, Ahmad ST, Aziz SA, et al (2014). Loss of expression and aberrant methylation of the CDH1 (E-cadherin) gene in breast cancer patients from Kashmir. Asian Pac J Cancer Prev, 15, 6397-403.

Asiaf A, Ahmad ST, Malik AA, et al (2015). Protein expression and methylation of MGMT, a DNA repair gene and their correlation with clinicopathological parameters in invasive ductal carcinoma of the breast. Tumor Biol, 12, 1-12.

Baylin SB, Ohm JE (2006). Epigenetic gene silencing in cancera mechanism for early oncogenic pathway addiction?. Nat Rev Cancer, 6, 107-16.

Baylln SB, Herman JG, Graff JR, et al (1997). Alterations in DNA methylation: a fundamental aspect of neoplasia. $A d v$ Cancer Res, 72, 141-96.

Bray F, Ferlay J, Soerjomataram I, et al (2018). Global cancer statistics 2018: GLOBOCAN estimates of incidence and mortality worldwide for 36 cancers in 185 countries. $C A$ Cancer J Clin, 68, 394-424.

Brock MV, Gou M, Akiyama Y, et al (2003). Prognostic importance of promoter hypermethylation of multiple genes in esophageal adenocarcinoma. Clin Cancer Res, 9, 2912-9.

Cancerindia.org.in. 2018. globocan--india-factsheet.

Christoph F, Kempkensteffen C, Weikert S, et al (2006). Methylation of tumour suppressor genes APAF-1 and DAPK-1 and in vitro effects of demethylating agents in bladder and kidney cancer. Br J Cancer, 95, 1701-7.

Cohen O, Feinstein E, Kimchi A(1997). DAP- kinase is a Ca2+/ calmodulin-dependent, cytoskeletal-associated protein kinase, with cell deathâ-inducing functions that depend on its catalytic activity. EMBO J, 16, 998-1008.

Cohen O, Inbal B, Kissil JL, et al (1999). DAP-kinase participates in TNF-alpha and Fas-induced apoptosis and its function requires the death domain. $J$ Cell Biol, 146, 141-8.

Dulaimi E, Hillinck J, de Caceres II, et al (2004). Tumor suppressor gene promoter hypermethylation in serum of breast cancer patients. Clin Cancer Res, 10, 6189-93.

Esteller M (2008). Epigenetics in cancer. N Engl J Med, 358, 1148-59.

Gheibi A, Kazemi M, Baradaran A, et al (2012). Study of promoter methylation pattern of 14-3-3 sigma gene in normal and cancerous tissue of breast: A potential biomarker for detection of breast cancer in patients. Adv Biomed Res, 1, 80 .

Gozuacik D, Kimchi A (2006). Review: Spotlight on cancer 
DAPk protein family and cancer. Autophagy, 2, 74-9.

Hafez MM, Al-Shabanah OA, Al-Rejaie SS, et al (2015). Increased hypermethylation of glutathione S-transferase P1, DNA-binding protein inhibitor, death associated protein kinase and paired box protein-5 genes in triple-negative breast cancer Saudi females. Asian Pac J Cancer Prev, 16, 541-9.

Inbal B, Cohen O, Polak-Charcon S, et al (1997). DAP kinase links the control of apoptosis to metastasis. Nature, $\mathbf{3 9 0}$, $180-4$.

Issa JP, Ahuja N (2000). Aging, methylation and cancer. Histol Histopathol, 15, 835-42.

Jovanovic J, Ronneberg JA, Tost Jr, et al (2010). The epigenetics of breast cancer. Mol Oncol, 4, 242-54.

Katzenellenbogen RA, Baylin SB, Herman JG (1999). Hypermethylation of the DAP-kinase $\mathrm{CpG}$ island is a common alteration in B-cell malignancies. Blood, 93, 4347-53.

Kuester D, Dar AA, Moskaluk CC, et al (2007). Early involvement of death-associated protein kinase promoter hypermethylation in the carcinogenesis of Barrett's esophageal adenocarcinoma and its association with clinical progression. Neoplasia (New York, NY), 9, 236.

Lehmann U, Celikkaya GL, Hasemeier B, et al (2002). Promoter hypermethylation of the death-associated protein kinase gene in breast cancer is associated with the invasive lobular subtype. Cancer Res, 62, 6634-8.

Levy D, Plu-Bureau GV, Decroix Y, et al (2004). Death-associated protein kinase loss of expression is a new marker for breast cancer prognosis. Clin Cancer Res, 10, 3124-30.

Raveh T, Droguett G, Horwitz MS, et al (2001). DAP kinase activates a p19ARF/p53-mediated apoptotic checkpoint to suppress oncogenic transformation. Nat Cell Biol, 3, 1-7.

Raveh T, Kimchi A (2001). DAP kinase- a proapoptotic gene that functions as a tumor suppressor. Exp Cell Res, 264, 185-92.

Rhodes A, Jasani B, Anderson E, et al (2002). Evaluation of HER-2/neu immunohistochemical assay sensitivity and scoring on formalin-fixed and paraffin-processed cell lines and breast tumors a comparative study involving results from laboratories in 21 countries. Am J Clin Pathol, 118, 408-17.

Rosas SLB, Koch W, da Costa Carvalho MdG, et al (2001). Promoter hypermethylation patterns of $\mathrm{p} 16$, O6-methylguanine-DNA-methyltransferase, and death-associated protein kinase in tumors and saliva of head and neck cancer patients. Cancer Res, 61, 939-42.

Simpson DJ, Clayton RN, Farrell WE (2002). Preferential loss of death associated protein kinase expression in invasive pituitary tumours is associated with either $\mathrm{CpG}$ island methylation or homozygous deletion. Oncogene, 21, 1217-24.

Sturgeon SR, Balasubramanian R, Schairer C, et al (2012). Detection of promoter methylation of tumor suppressor genes in serum DNA of breast cancer cases and benign breast disease controls. Epigenetics, 7, 1258-67.

Tan J, Gu Y, Zhang X, et al (2012). Hypermethylation of CpG islands is more prevalent than hypomethylation across the entire genome in breast carcinogenesis. Clin Expe Med, 13, 1-9.

Yuan N, Meng M, Liu C, et al (2014). Clinical characteristics and prognostic analysis of tripleâ€'negative breast cancer patients. Mol Clin Oncol, 2, 245-51.

Zhao X-L, Meng Z-Y, Qiao Y-H, et al (2008). Promoter methylation of DAPK gene in cervical carcinoma. Chin J Cancer, 27, 212-5.

Zochbauerr-Muller S, Fong KM, Virmani AK, et al (2001). Aberrant promoter methylation of multiple genes in non-small cell lung cancers. Cancer Res, 61, 249-55.

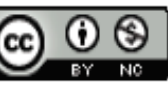

This work is licensed under a Creative Commons AttributionNon Commercial 4.0 International License. 